Supporting Information

\title{
"Well-Defined Fullerene-containing Homopolymers and Diblock Copolymers with High Fullerene Content and Their Use for Solution-Phase and Bulk Organization”
}

\author{
Zachary T. Ball, Kevin Sivula, and Jean M. J. Fréchet*
}

718 Latimer Hall, Department of Chemistry, University of California, Berkeley, 94720-1460

\author{
frechet@cchem.berkeley.edu
}

\section{General}

All reactions were performed under nitrogen atmosphere unless otherwise indicated. Solvents were purified on a solvent purification column. The complex [( $\left.\mathrm{H}_{2} \mathrm{IMes}\right)(3-$

bromopyridine $)_{2}(\mathrm{Cl})_{2} \mathrm{Ru}=\mathrm{CHPh}$ (5) was prepared as previously described. ${ }^{[1]}$ All other reagents were purchased and used as received.

Flash chromatography was performed with silica gel (NBS Biologicals 32-63D, $60 \AA$ ).

Analytical thin layer chromatography was performed with 0.2 -mm coated commercial silica gel plates (E. Merck, DC Plastifolien, kieselgel 60 F254).

Proton and broad-band decoupled ${ }^{13} \mathrm{C}$ nuclear magnetic resonance data were acquired on a Bruker AV-300, AVQ-400 or AVB-400 spectrometer as indicated. Chemical shifts are reported in ppm relative to TMS solvent as an internal standard.

\section{Synthesis of Monomer 4}

4-Aminomethyl benzyl alcohol ${ }^{[2]}$ (400 mg, $2.9 \mathrm{mmol}$ ) and cis-5-Norbornene-exo-2,3dicarboxylic anhydride (368 mg, $2.24 \mathrm{mmol}$ ) were taken up in toluene ( $30 \mathrm{~mL}$ ). The flask was affixed with a Dean-Stark trap, and the mixture refluxed overnight. Removal of the toluene in vacuo and purification of the crude mixture on a silica gel column (eluent: 3:1, then 2:1 hexanes: EtOAc) provided $610 \mathrm{mg}$ (96\%) of the desired alcohol (2) as a colorless viscous gum.

${ }^{1} \mathrm{H}$ NMR (300 MHz, CDCl $) \delta 7.35$ (d, $\left.J=8.1 \mathrm{~Hz}, 2 \mathrm{H}\right), 7.29$ (d, $\left.J=8.1 \mathrm{~Hz}, 2 \mathrm{H}\right), 6.27(\mathrm{~s}, 2 \mathrm{H})$, 4.65 (s, 2H), 4.60 (s, 2H), 3.24 (br s, 2H), 2.67 (s, 2H), 2.04 (br s, 1H), 1.42 (d, J = 9.9 Hz, 1H), $1.27(\mathrm{~m}, 1 \mathrm{H}), 1.05(\mathrm{~d}, J=9.9 \mathrm{~Hz}, 1 \mathrm{H}) .{ }^{13} \mathrm{C}$ NMR $\left(75 \mathrm{MHz}, \mathrm{CDCl}_{3}\right) \delta 177.7,140.6,137.9,135.1$, 129.1, 127.2, 64.8, 47.7, 45.2, 42.6, 42.0.

Meldrum's acid (395 mg, $2.74 \mathrm{mmol}$ ) and 3,5-dioctyloxybenzyl alcohol (1.0 g, $2.74 \mathrm{mmol}$ ) were heated neat at $120^{\circ} \mathrm{C}$ for $4 \mathrm{~h}$. The mixture was then cooled to rt and placed under vacuum (ca. 1 torr) for $3 \mathrm{~h}$. The crude acid ( $670 \mathrm{mg}, 1.49 \mathrm{mmol}$ ), together with alcohol 2 (383 mg, $1.24 \mathrm{mmol}$ ) and DMAP (18 mg, $0.12 \mathrm{mmol}$ ) were taken up in $\mathrm{CH}_{2} \mathrm{Cl}_{2}(6 \mathrm{~mL})$ at $0{ }^{\circ} \mathrm{C}$ and the mixture was 
treated with DCC (368 mg, $1.49 \mathrm{mmol}$ ). The flask was allowed to warm to rt overnight, and the mixture was then applied directly to silica gel column (eluent: 10:1, then 4:10 hexanes: EtOAc) to afford $730 \mathrm{mg}(83 \%)$ of the desired diester 3.

${ }^{1} \mathrm{H}$ NMR (300 MHz, $\left.\mathrm{CDCl}_{3}\right) \delta 7.35(\mathrm{~d}, J=8.1 \mathrm{~Hz}, 2 \mathrm{H}), 7.26(\mathrm{~d}, J=8.1 \mathrm{~Hz}, 2 \mathrm{H}), 6.45(\mathrm{~d}, J=2.1$ Hz, 2H), 6.34 (s, 1H), 6.26 (s, 2H), 5.13 (s, 2H), 5.07 (s, 2H), 4.60 (s, 2H), 3.91 (t, J = 6.6 Hz, 4H), 3.46 (s, 2H), 3.24 (br s, 2H), 2.67 (s, 2H), 1.75 (m, 4H), $1.20-1.45(\mathrm{~m}, 22 \mathrm{H}), 0.87$ (t, $J=$ $6.8 \mathrm{~Hz}, 6 \mathrm{H}) .{ }^{13} \mathrm{C}$ NMR $\left(75 \mathrm{MHz} \mathrm{CDCl}_{3}\right) \delta 177.8,166.1,165.9,160.4,137.8,137.2,106.4$, 101.1, 68.1, 67.2, 61.8, 47.8, 45.2, 42.7, 41.2, 37.3, 31.8, 29.3, 29.2, 26.0, 22.6, 14.1. Anal. Calc. for $\mathrm{C}_{43} \mathrm{H}_{57} \mathrm{NO}_{8}$ : C, 72.14; H, 8.03; N, 1.96. Found: C, 72.00; H, 8.30; N, 2.10.

The diester 3 (411 mg, $0.574 \mathrm{mmol}$ ), solid $\mathrm{C}_{60}$ (413 mg, $0.574 \mathrm{mmol}$ ), and carbon tetrabromide (228 mg, $0.689 \mathrm{mmol})$ were taken up in toluene $(250 \mathrm{~mL})$ at rt and treated with DBU $(172 \mu \mathrm{L}$, $1.15 \mathrm{mmol}$ ). the solution was stirred for $18 \mathrm{~h}$. The solution was then passed through a silica gel plug (ca. $5 \mathrm{~cm}$ ), eluting first with toluene to collect unreacted $\mathrm{C}_{60}$ (which was recycled), then with 20:1 $\mathrm{CH}_{2} \mathrm{Cl}_{2}$ /methanol to elute more polar colored ( $\mathrm{C}_{60}$-containing) fractions. The second fraction was then concentrated in vacuo and applied to a silica gel column (eluent: 100:0, then 100:1 $\mathrm{CH}_{2} \mathrm{Cl}_{2}$ :ether). Product-containing fractions were concentrated in vacuo to ca. $20 \mathrm{~mL}$, and the dark purple solution was added to methanol $(200 \mathrm{~mL})$ with stirring to precipitate the product. Decanting the solvents and drying of the dark solid in vacuo afforded $390 \mathrm{mg}$ (47\%) of the desired monoadduct 4.

m.p. $=94-98{ }^{\circ} \mathrm{C} .{ }^{1} \mathrm{H}$ NMR (300 MHz, $\left.\mathrm{CDCl}_{3}\right) \delta 7.38$ (s, 4H), 6.55 (d, $\left.J=2.1 \mathrm{~Hz}, 2 \mathrm{H}\right), 6.40$ (s, $1 \mathrm{H}), 6.26(\mathrm{~s}, 2 \mathrm{H}), 5.44(\mathrm{~s}, 2 \mathrm{H}), 5.38(\mathrm{~s}, 2 \mathrm{H}), 4.61(\mathrm{~s}, 2 \mathrm{H}), 3.90(\mathrm{t}, J=6.5 \mathrm{~Hz}, 4 \mathrm{H}), 3.47$ (AB, $J=$ $6.9 \mathrm{~Hz}, 2 \mathrm{H}), 3.25$ (br s, 2H), 2.67 (s, 2H), 1.73 (m, 4H), $1.20-1.45$ (m, 22H), 0.87 (t, J = 6.8 Hz, $6 \mathrm{H})$. MS-FAB+ (m/z): [M+ H $]^{+}$calcd for $\mathrm{C}_{103} \mathrm{H}_{56} \mathrm{O}_{8}$ : 1434.3; found: 1433.7. Anal. Calc. for $\mathrm{C}_{103} \mathrm{H}_{55} \mathrm{NO}_{8}$ : C, 86.24; H, 3.86; N, 0.98. Found: C, 84.44; H, 3.66; N, 1.03.

\section{General ROMP procedure for the preparation of homopolymer.}

Norbornene derivative 4 (36.8 mg, $25.7 \mu \mathrm{mol}$ ) and ruthenium carbene 5 (0.96 mg, $1.08 \mu \mathrm{mol}$ ) were placed together with a magnetic stir bar in a screw-top vial with a Teflon septa. The vial was evacuated and back-filled with $\mathrm{N}_{2}$ three times. $\mathrm{CH}_{2} \mathrm{Cl}_{2}(0.3 \mathrm{~mL})$ was then introduced via syringe and the solution stirred for $4 \mathrm{hr}$. Ethyl vinyl ether (ca. $3 \mu \mathrm{L}$ ) was added via syringe, and the mixture stirred for $1 \mathrm{~h}$. The mixture was then diluted with chlorobenzene to ensure complete solubility $(1.5 \mathrm{~mL})$, and the solution was added dropwise to ether $(15 \mathrm{~mL})$ with stirring. The polymer precipitate was collected by filtration on a frit, and was dried in vacuo to afford $31 \mathrm{mg}$ $(84 \%)$ of the desired poly $(4)_{25}$.

Figure S- $1 .{ }^{1} \mathrm{H}$ NMR (300 MHz) of poly(4) ${ }_{25}$ in 2:1 $\mathrm{SC}_{2}: \mathrm{CDCl}_{3}$ mixture. 


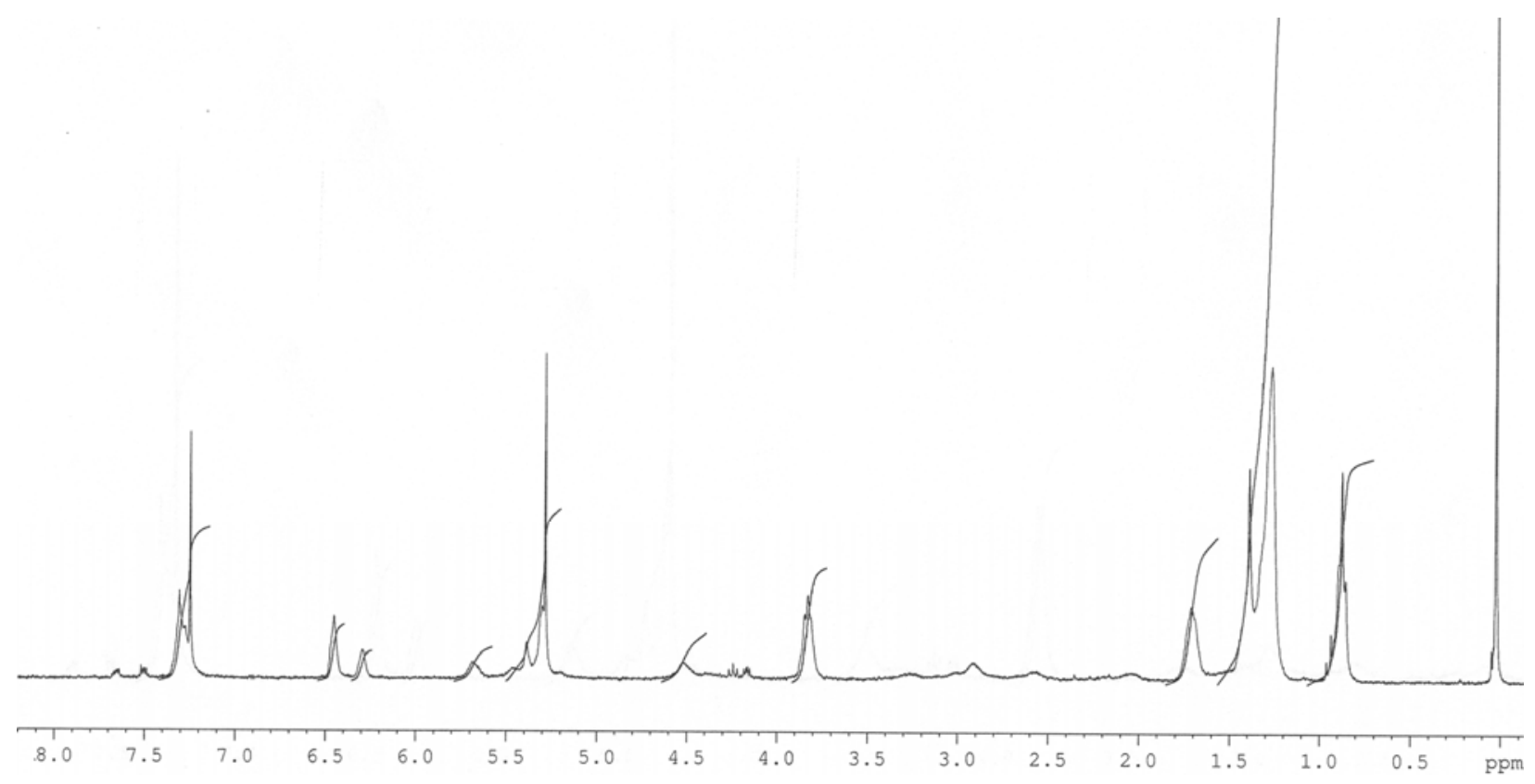

\section{General ROMP procedure for the preparation of diblock copolymers.}

The G-2 dendron 6 (27 mg, $49.2 \mu \mathrm{mol})$ and ruthenium carbene 5 (0.44 mg, $0.49 \mu \mathrm{mol})$ were placed together with a magnetic stir bar in a screw-top vial with a Teflon septa. The vial was evacuated and back-filled with $\mathrm{N}_{2}$ three times. Degassed chlorobenzene $\left(0.2 \mathrm{~mL}, \mathrm{CH}_{2} \mathrm{Cl}_{2}\right.$ could also be employed with equal success) was then introduced via syringe and the solution stirred for $45 \mathrm{~min}$. A chlorobenzene solution of $\mathrm{C}_{60}$-bearing monomer 4 (25 mg, $17 \mu \mathrm{mol}$ in $0.2 \mathrm{~mL}$ solvent) was the introduced via syringe. The solution was stirred for $14 \mathrm{hr}$. The mixture was then diluted with chlorobenzene $(1.5 \mathrm{~mL})$, and the solution was added dropwise to ether $(15 \mathrm{~mL})$ with stirring. The polymer precipitate was collected by filtration on a frit, and was dried in vacuo to afford $42 \mathrm{mg}(81 \%)$ of the desired poly(6) 100 $_{\text {-block-poly(4) }}$. The GPC, though polymodal, shows no evidence of the presence of $\operatorname{poly}(\mathbf{6})_{100}$, which was synthesized separately by the same procedure given for the synthesis of homopolymers, with precipitation into methanol instead of ether.

Figure S- 2. ${ }^{1} \mathrm{H}$ NMR (300 MHz) of poly(6) $)_{100}$-block-poly(4) $)_{35}$ in $\mathrm{CDCl}_{3}$. 


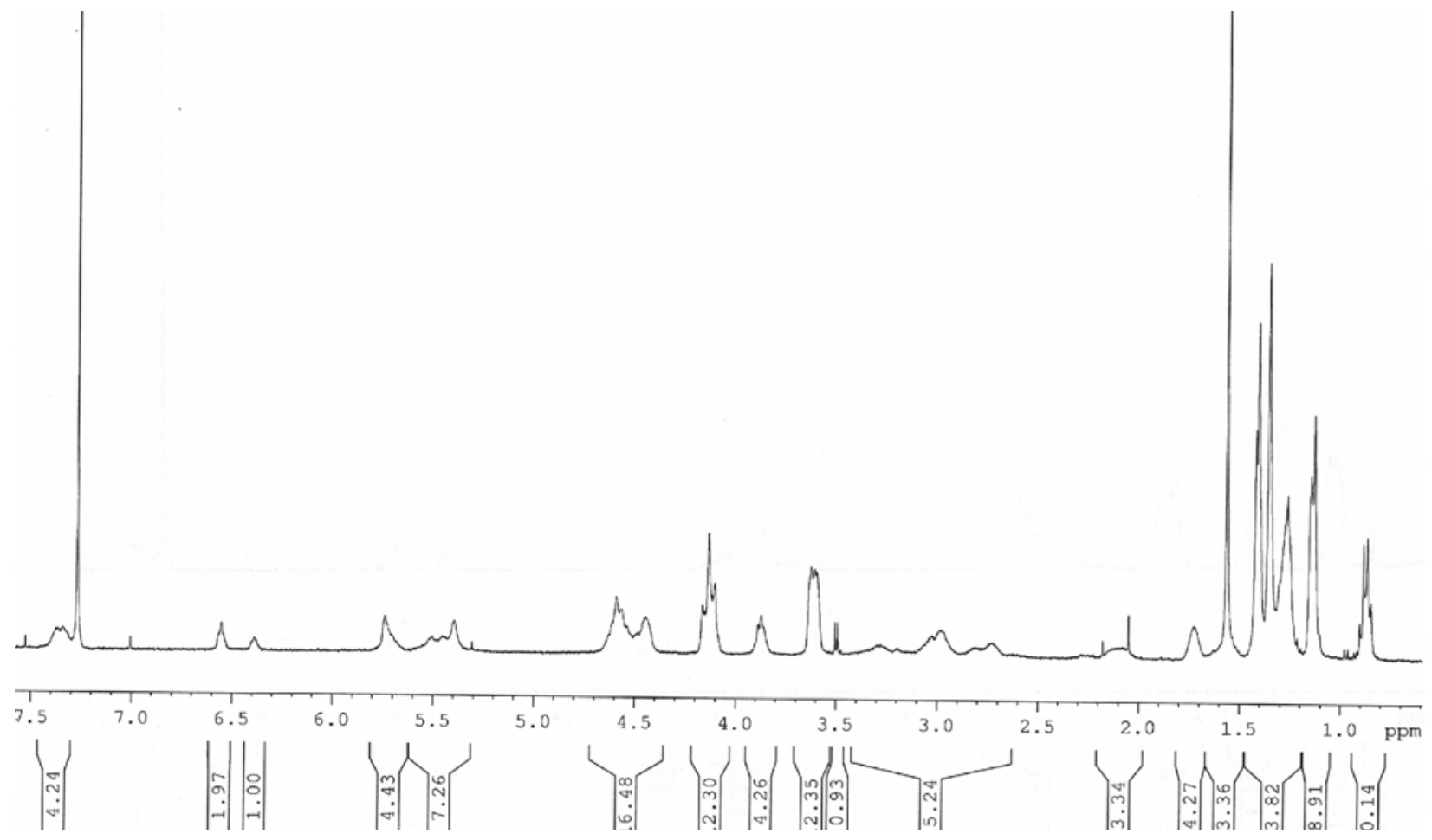

Figure S- 3 SEC analysis of poly(6) $)_{100}$ (a) and poly(6) $)_{100}$-block-poly(4) $)_{35}$. solvent, $\mathrm{CHCl}_{3}$; flow rate, $1.0 \mathrm{mg}, \mathrm{mL}$. Other diblock polymer ratios afforded similar SEC traces. 


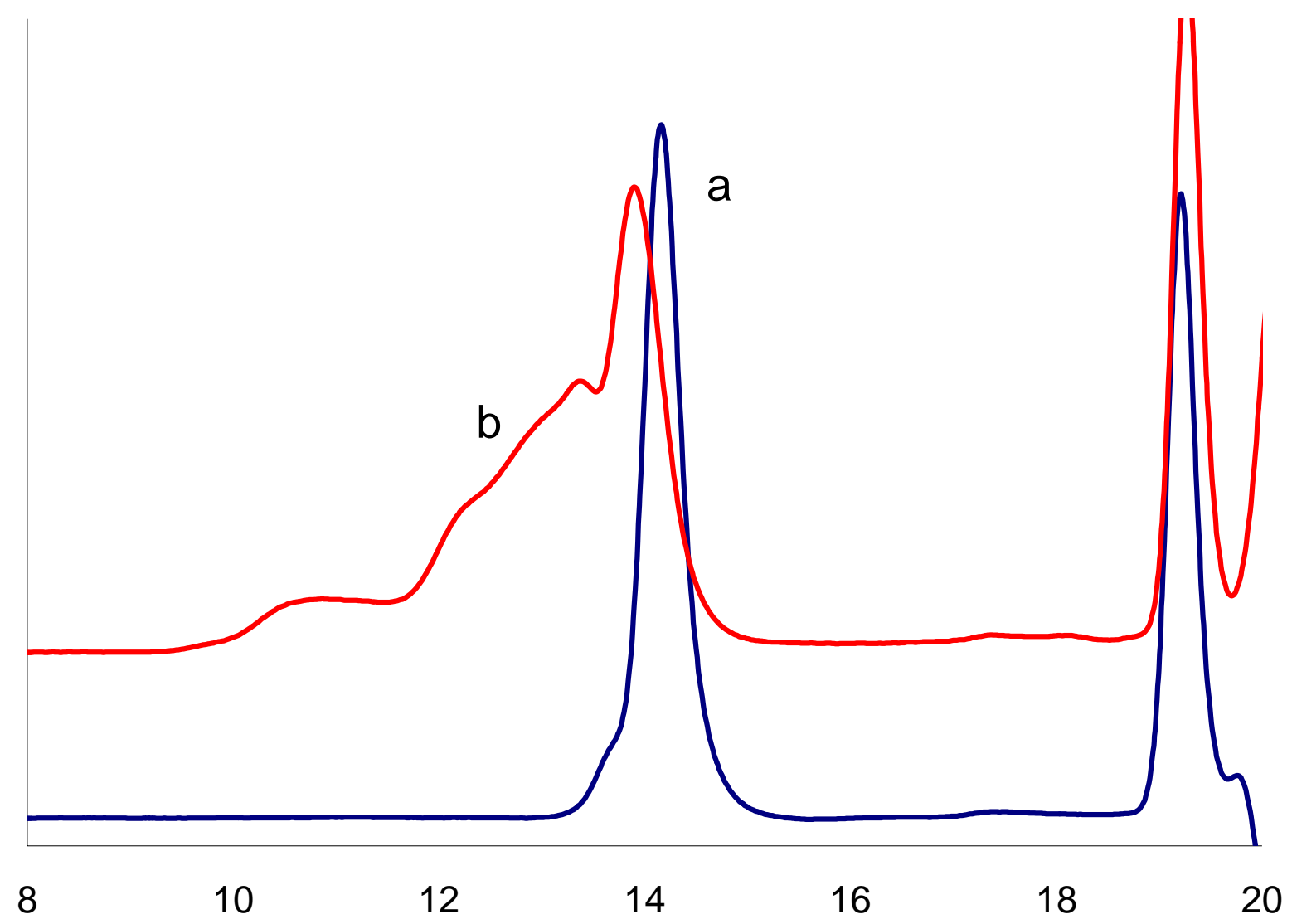

Figure S- 4. DLS size analysis of poly(6) $)_{25}$. Measurements taken in $\mathrm{CHCl}_{3}$ solution $(1 \mathrm{mg} / \mathrm{mL})$ at $20{ }^{\circ} \mathrm{C}$.

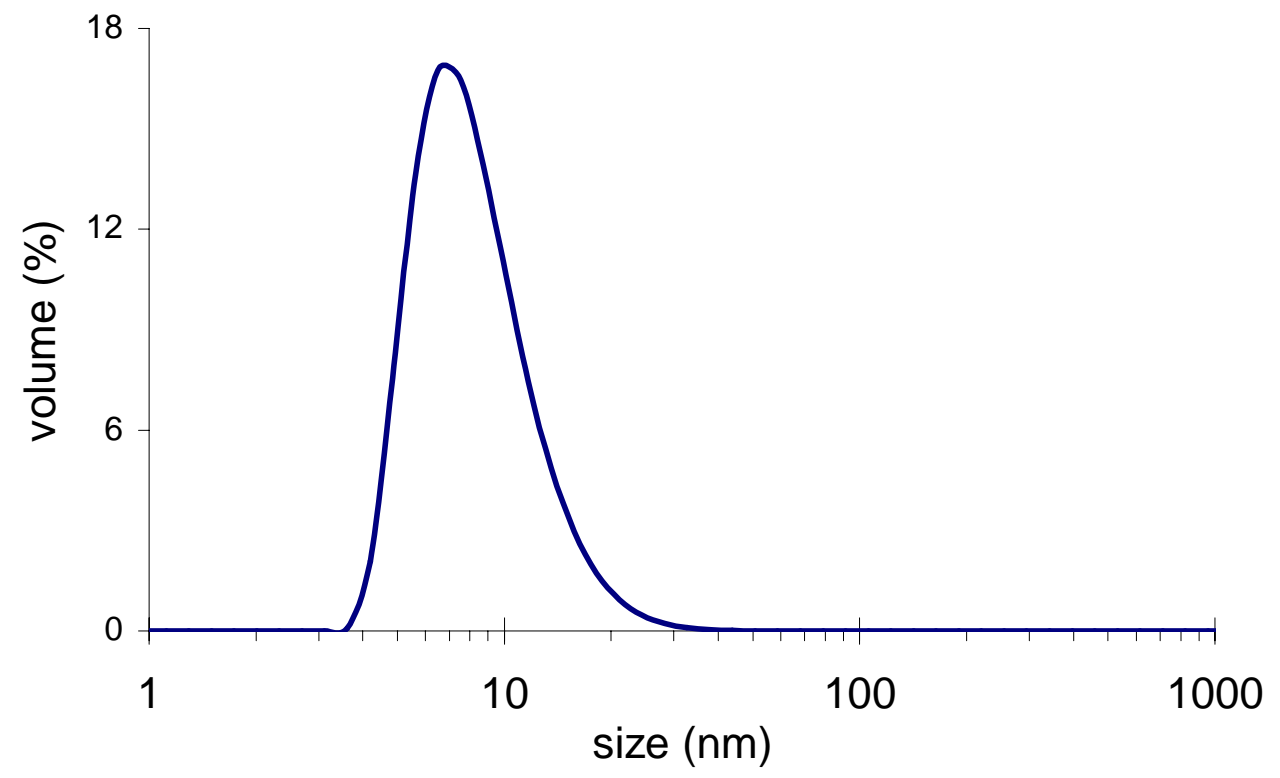


Figure S- 5. DLS size analysis of poly(6) $)_{35}$-block-poly(4) $)_{200}$ Measurements taken in $\mathrm{CHCl}_{3}$ solution $(1 \mathrm{mg} / \mathrm{mL})$ at $20^{\circ} \mathrm{C}$. Relative size of peaks varied significantly from measurement to measurement with the same sample; shown below is a representative example.

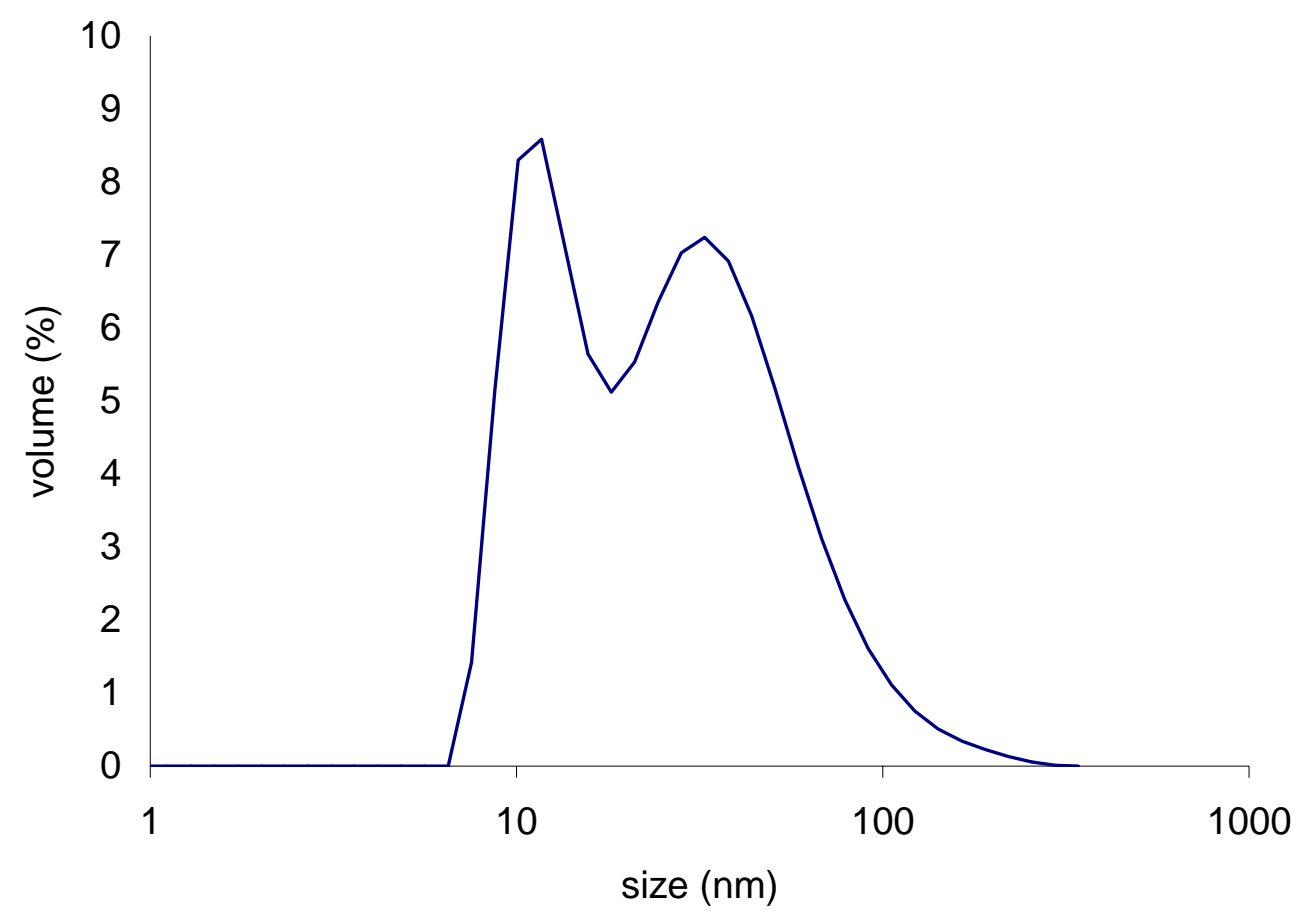

Figure S-6. TGA analysis of poly $(6)_{70}$-block-poly(4) $)_{35}$. Mass loss is given as a function of temperature (a) and of time (b) to show behavior during holding period at $500{ }^{\circ} \mathrm{C}$. 


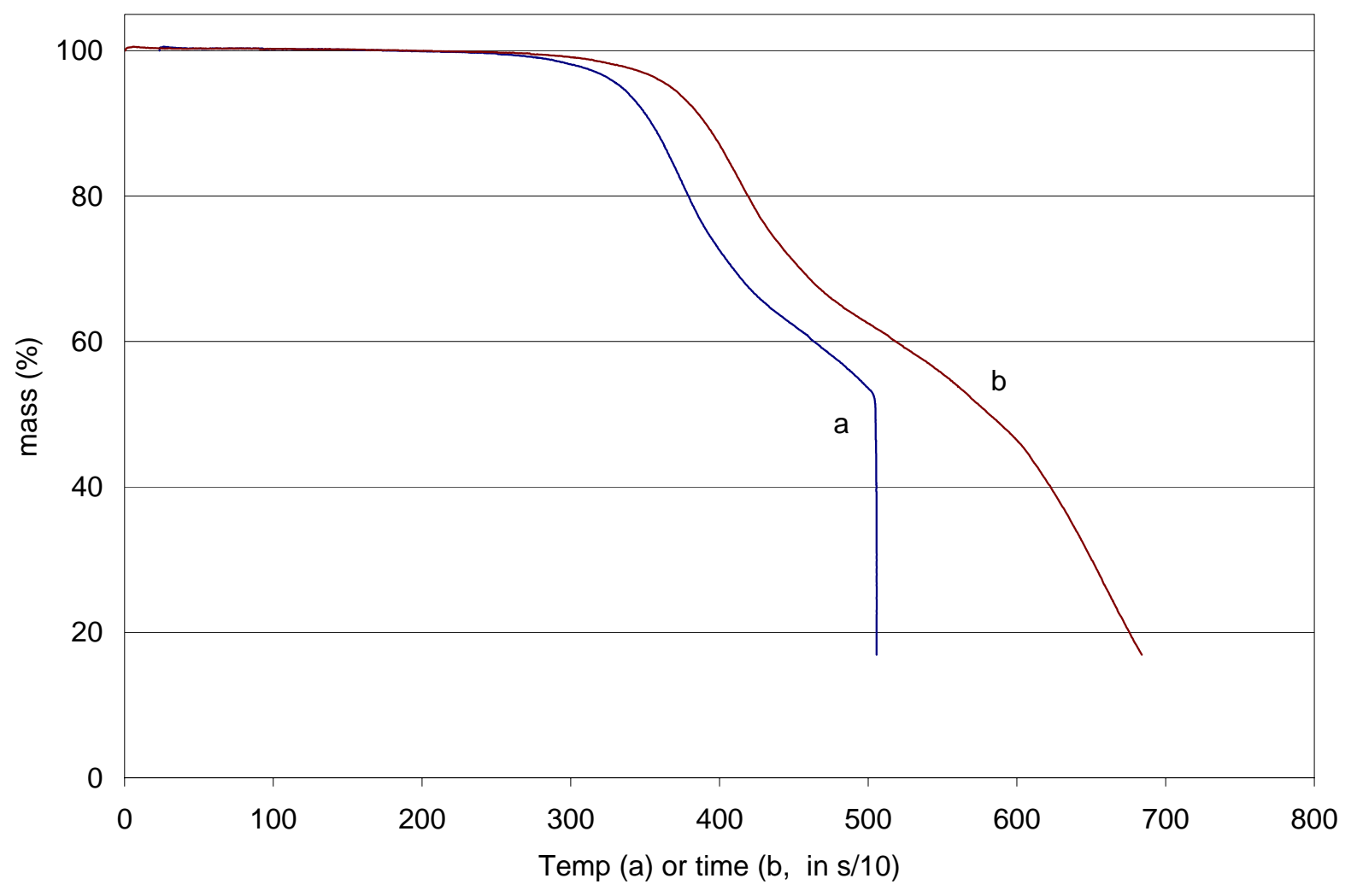

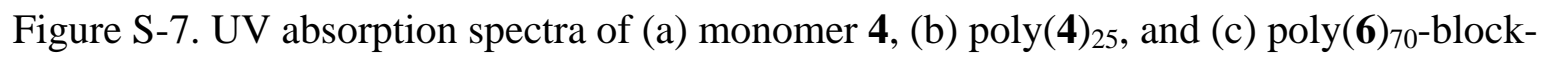
poly(4) $)_{35}$ recorded in $\mathrm{CHCl}_{3}$, with expansion below. 

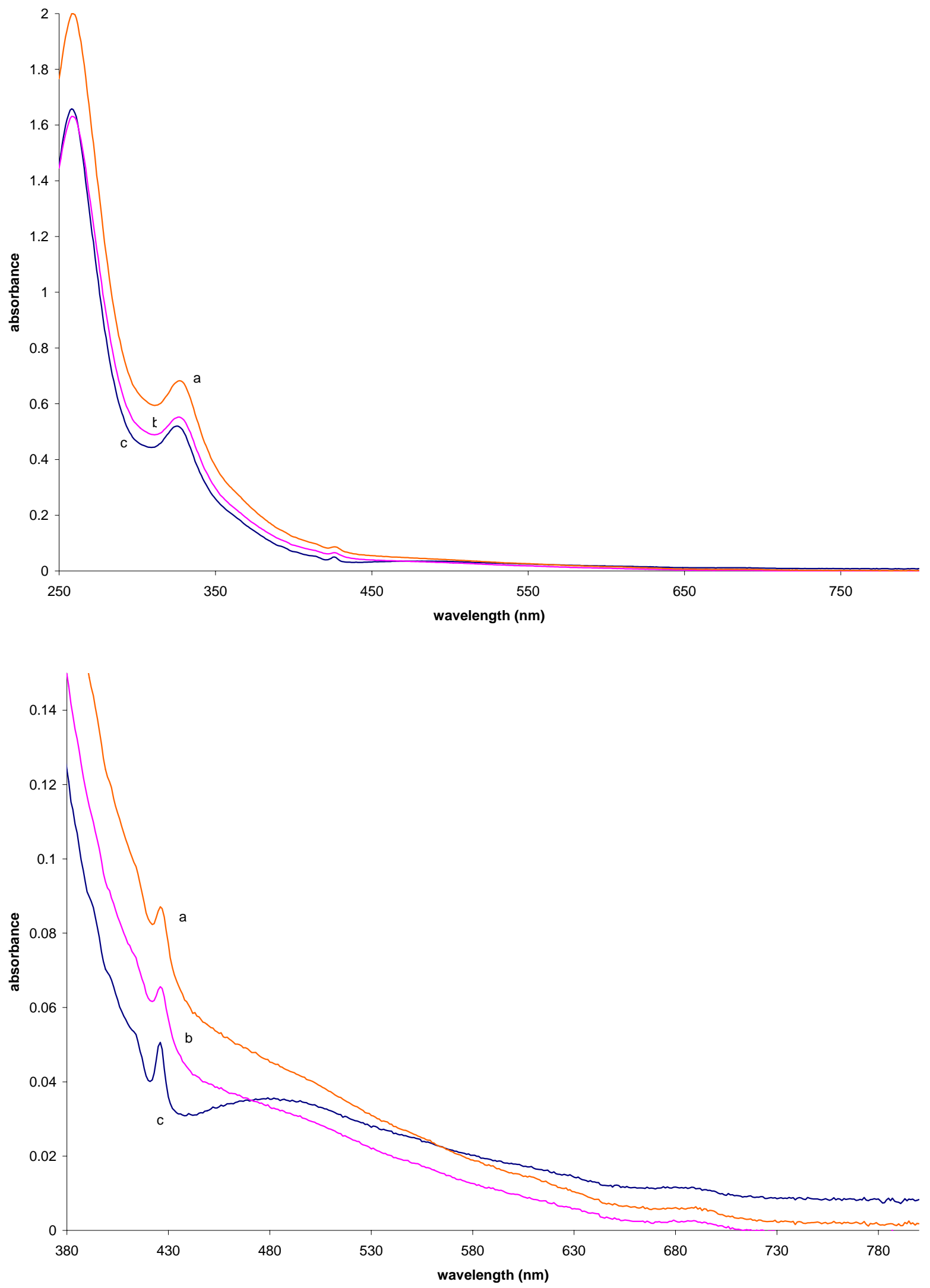
[1] J. A. Love, J. P. Morgan, T. M. Trnka, R. H. Grubbs, Angew. Chem., Int. Ed. Engl. 2002, 41, 4035-4037.

[2] J. Lee, J. Lee, M. Kang, M. Shin, J.-M. Kim, S.-U. Kang, J.-O. Lim, H.-K. Choi, Y.-G. Suh, H.-G. Park, U. Oh, H.-D. Kim, Y.-H. Park, H.-J. Ha, Y.-H. Kim, A. Toth, Y. Wang, R. Tran, L. V. Pearce, D. J. Lundberg, P. M. Blumberg, J. Med. Chem. 2003, 46, 31163126. 